\title{
5.1
}

\section{Participação social na construção do SUS: uma análise à luz da experiência brasileira}

Social participation on the building of the Brazilian Health System: an analysis on the Brazilian experience

\begin{abstract}
Alinne Martins Conserva
Enfermeira, Especialista em Enfermagem Obstétrica. Enfermeira do Hospital Regional da Asa Norte da Secretaria de Saúde do Distrito Federal. Brasília, Brasil.
\end{abstract}

\section{Fabiana Mendes Fonseca Taveira}

Bacharel em Biomedicina e Direito, Especialista em Direito Civil. Servidora da Vigilância Sanitária da Secretaria de Estado de Saúde do Distrito Federal. Brasília, Brasil.

\section{Luanna de Mendonça Gomes}

Farmacêutica, Especialista em Gestão de Saúde. Farmacêutica do Laboratório Central de Saúde Pública da Secretaria de Estado de Saúde do Distrito Federal. Brasília, Brasil.

\section{Paulino da Silva Marinho \\ Enfermeiro. Analista-Técnico de Políticas Sociais do Ministério da Saúde. Brasília, Brasil}

\section{Rosa Shirley Peres da Silva \\ Biomédica. Brasília-DF, Brasil.}

Resumo: Este artigo se propõe a descrever e analisar a participação social na construção do SUS, com base em análise de experiências descritas em artigos recentes. Partiu-se do seguinte pressuposto teórico: as conquistas realizadas no processo de democratização da saúde brasileira e a participação exercida nos conselhos de saúde prenunciam uma nova política, que inclui novos participantes na saúde pública. O processo permite novo direcionamento da cultura política em busca de decisões mais democráticas. Foi realizada revisão bibliográfica integrativa nas bases Scielo, Lilacs e Bireme. Recorreu-se à técnica de pesquisa de artigos com o objetivo de analisar a literatura recente relacionada à construção do SUS por meio de debates e lutas de movimentos sociais. Nos estudos surgidos, identificou-se que a cultura política tradicional se tornou dinâmica e complexa e permitiu que o Movimento de Reforma Sanitária impulsionasse mudanças sociais com o entendimento de que todos possuem efetivo direito à saúde. Foi observado, ainda, que existem entraves que dificultam a participação e o controle social, o que nos permite afirmar que o processo democrático no Brasil ainda carece de desenvolvimento.

Palavras chave: Controle social; conselho de saúde; conferência de saúde; participação social.

Resumen: Este artículo se propone describir y analizar la participación social en la construcción de SUS, con base en el análisis de experiencias descriptas en artículos recientes. Partiendo del siguiente presupuesto teórico: Las conquistas realizadas en el proceso de democratización de la salud brasilera y la participación ejercida en los 
Consejos de Salud predicen una nueva política, que incluye nuevos participantes en la salud pública. El proceso permite un nuevo direccionamiento de la cultura política en busca de decisiones más democráticas. Fue realizada una revisión bibliográfica integral con bases en Scielo, Lilacs y Bireme. Se utilizó la técnica de investigación de artículos con el objetivo de analizar la literatura reciente relacionada con la construcción de SUS por medio de debates y luchas de los movimientos sociales. En los estudios surgidos, se identificó que la cultura política tradicional, se tornó dinámica y compleja, lo que permitió que el Movimiento de la Reforma Sanitaria, impulsara cambios sociales con el entendimiento de que todos poseen un derecho efectivo a la salud. Fue observado, además, que existen trabas que dificultan la participación y el control social, lo que nos permite afirmar que el proceso democrático de Brasil todavía carece de desarrollo.

Palabras claves: Control social; consejo de salud; conferencia de salud; participación social.

Abstract: This article aims to describe and analyze the social participation in the construction of SUS, based on an analysis of the experiences described in recent articles. This started from the following theoretical assumption: The achievements made in the democratization process of the Brazilian health and participation in health councils exercised herald a new policy, which includes new participants in public health. The new process allows targeting of political culture in search of more democratic decisions. Techniques of qualitative research based on integrative literature review in the Scielo, Lilacs and Bireme were used. Resorted to the technique of search form in order to analyze the recent literature related to construction of SUS through debates and struggles of social movements. Encountered in studies, we found that the traditional political culture has become dynamic and complex and allowed the Health Reform Movement boosts social changes with the understanding that everyone has the right to effective healthcare. It was also noted that there are barriers that prevent participation and social control, which allows us to state that the democratic process in Brazil still lacks development.

Key-words: Social control; Board of Health; health and social participation.

\section{Introdução}

O Sistema Único de Saúde, criado no Brasil pela Constituição Federal de 1988, nasceu de um processo de lutas e debates que envolveu a participação de vários segmentos sociais unidos, conhecido como Movimento de Reforma Sanitária. Esse movimento, influenciado pelos anseios sociais da época de reintroduzir a democracia no país, levou ao surgimento de diversos espaços de reivindicações populares para a criação de uma política pública voltada para a saúde dos cidadãos brasileiros que garantisse o acesso universal, integral e equânime às ações e serviços de saúde. 
As reivindicações pela redemocratização no Brasil, durante um longo período de regime de ditadura, resultaram na conquista de uma reforma constituinte que transformou o país em um Estado Democrático de direito, ou seja, um Estado rico em direitos positivados em sua constituição, inclusive o direito à participação direta por parte de seus cidadãos nas políticas públicas.

Os direitos sociais preconizam a prática participativa e o setor saúde serve de modelo para essa prática, pois se trata de uma política social que possui como um de seus princípios organizativos a participação social. O SUS é tido como a política de maior inclusão social já implementada no Brasil e representa uma firmação política do compromisso do Estado brasileiro para com seus cidadãos. (Santos e Bastos, 2011).

A participação social se trata do engajamento através da ação, do desafio da proposição e do controle dos fatos e feitos. (Brutscher, 2012). Porém, apesar de institucionalizada por meio de instâncias asseguradas na Constituição Federal e na Lei no 8142 , de 1990, a participação social na saúde, por meio de seus conselhos e conferências, ainda encontra barreiras para se efetivar como parte do cotidiano e prática permanente dos cidadãos para além desses espaços institucionalizados.

Este artigo tem por objetivo a análise, à luz da experiência brasileira, da participação social no Sistema Único de Saúde como instrumento para efetivação da democracia e da cidadania para além dos espaços dos conselhos e conferências de saúde, bem como analisar sua contribuição para o processo de construção do SUS.

\section{Metodologia}

O presente artigo foi construído a partir da revisão bibliográfica de trabalhos publicados, cujo tema tratou da experiência brasileira e dos mecanismos institucionalizados de participação social estabelecidos na Constituição e nas Leis Orgânicas de saúde no Brasil.

A metodologia utilizada foi a de levantamento, utilizando-se a pesquisa nas bases de dados Scielo, Lilacs e Bireme, a partir dos descritores Participação Social, Controle Social, Conselhos de Saúde e Conferência de Saúde. A pesquisa considerou 08 artigos brasileiros publicados de 2011 a 2014, cujas metodologias adotaram uma abordagem teórica. Inicialmente foram selecionados 34 artigos, e após a análise e aplicação dos critérios de exclusão foram retirados 28 destes, por adotarem método exploratório a partir de regiões brasileiras, com análise de universos divergentes e que não correspondiam ao objetivo dos autores no momento. 


\section{Resultados e discussão}

\section{Participação e Controle Social}

Historicamente o SUS, assegurado e estabelecido a partir da Constituição de 1988, foi uma conquista de iniciativa popular, onde as ações de saúde se tornaram finalmente democráticas. A partir disso, saúde é agora direito de todos e dever do Estado, porém muitas barreiras tiveram que ser quebradas para que se chegasse a esse ideal. O fim do período da ditadura militar (1964-1985) no Brasil foi estimulado pelos movimentos sociais que criticavam duramente o regime, no qual as políticas públicas seriam parte de um modelo unificado que não favorecia, pelo contrário, marginalizava ainda mais as camadas socioeconomicamente vulneráveis da sociedade, e a perspectiva de controle social era de domínio do Estado. (Amorim et. al, 2012; Santos; Bastos, 2011)

O Movimento de Reforma Sanitária, contrário aos ideais daquele regime, encorajou e impulsionou as novas mudanças sociais a partir da consciência do direito à saúde, inclusive no que se estabeleceu posteriormente na Reforma Constituinte que resultou na Constituição vigente e no Estado democrático de direito no qual estamos inseridos atualmente, que assegura e permite o exercício da democracia, efetivação de direitos com controle social e transparência. (Brutscher, 2012)

O processo democrático brasileiro por ser dinâmico se torna complexo, pois além de evoluir concomitantemente com a sociedade ao logo do tempo, envolve conceitos pouco assimilados pela maioria de seus constituintes como: 0 reconhecimento do indivíduo como parte de uma sociedade; o reconhecimento de seus direitos e deveres, bem como sua atuação dentro do espaço onde está inserido. Este último, sendo marcante, pois é capaz de colocar o indivíduo como cidadão ativo dentro da sociedade sendo agora capaz de modificar, fiscalizar e até mesmo monitorar os entraves estabelecidos entre Estado e sociedade civil (Amorim et. al, 2012; Santos; Bastos, 2011).

Nesse contexto os princípios e diretrizes que conduzem o SUS, por meio da Lei 8080/90, como a universalidade de acesso a saúde, integralidade da assistência, equidade, descentralização, participação popular, regionalização e hierarquização, favoreceram e atribuíram ao cidadão, agora usuário do sistema, dentro do contexto social dessa política pública, a responsabilidade de se reconhecer como parte fundamental para que esse direito seja garantido, havendo assim um empoderamento instituído legalmente. (Amorim et.al, 2012; Brutscher, 2012; Rolim; Cruz e Sampaio, 2013; Santos; Bastos, 2011).

A participação e o controle social permitem que população seja parte integrante desde 0 processo inicial de formulação das políticas públicas até a fiscalização perante a atuação do Estado. Essas conquistas são comprometidas pela falta de consciência cidadã, acarretando em patologias sociais que acabam por se tornar crônicas, pois não são superadas, tendo em vista os problemas que se arrastam ao longo do tempo e sendo um entrave para o desenvolvimento de novos mecanismos de atuação (Rolim; Cruz e Sampaio, 2013).

Essa notória falta de politização e, por conseguinte, encorajamento para que o indivíduo se reconheça e atue de fato, como cidadão e consequentemente agente 
participativo, torna essa meta difícil de ser alcançada. Se não houver avanços em busca de uma sociedade mais consciente e detentora de seus direitos e deveres, continuaremos apenas a tentar resolver os problemas com paliativos que escondem o que realmente precisa ser reformado.

Assim, a participação social no âmbito da saúde não pode ser apenas uma extensão da legalidade instituída, mas deve caminhar ao lado do processo democrático e sua evolução política, histórica, cultural e social. Nesse sentido, as transformações da sociedade devem ser acompanhadas de mecanismos que tornem essa política mais dinâmica e mais próxima da realidade temporal. (Amorim et. al, 2012; Santos; Bastos, 2011)

Os canais de participação popular foram criados e estabelecidos pela Lei 8.142/90 para promover um espaço de mediação de conflitos e principalmente aprimorar o processo de controle social das políticas de saúde, na tentativa de se defender os interesses coletivos acima dos individuais. (Brasil, 1990)

Porém, vale ressaltar que esse processo se apresenta burocrático demais ao usuário que possui menos acesso, ou seja, aquele que não possui a apropriação de seus diretos por falta de conhecimento, e que representa a grande parte dos usuários do sistema. Essa defasagem política e educacional permite que este usuário, já tutelado positivamente pelos Conselhos, fique alheio às decisões de outros que buscam legitimamente escolhas democráticas e conscientes para manutenção dos princípios do direito à saúde, mas que podem conduzir seus discursos na busca de privilégios e interesses de grupos específicos. Restam os canais de ouvidorias e reclamações aos usuários, e por consequência, a participação e o controle social perdem o contexto interdisciplinar, no qual se enquadram atualmente.

Percebe-se que ainda existem entraves que dificultam a participação e por consequência o controle social na saúde pública, o que corrobora com a ideia de que - processo democrático das políticas de saúde no Brasil ainda precisa ser aprimorado. Apesar destas duas interpretações (participação e controle social) se diferenciarem conceitualmente, elas se complementam. Para alguns autores, elas são tratadas, inclusive como sinônimas, em que uma não se esgota no processo de intervenção decisória individual e invade a outra, sendo capaz de coletivamente afetar de forma positiva as ações do Estado em favor do bem comum e da execução das políticas de saúde (Brutscher, 2012; Santos; Bastos, 2011).

Nessa perspectiva, a linha tênue entre essas duas concepções abarca problemas que extrapolam a concepção de participação, envolvendo também a atuação coletiva e influenciando diretamente na busca pelo Estado Democrático de direito real, na conquista dos direitos sociais e na implementação do SUS, enquanto a maior política social brasileira positivada que traz em seu bojo a participação popular. (Brutscher, 2012; Santos; Bastos, 2011).

\section{A participação social institucionalizada: conferências e conselhos de saúde}

Ancoradas nos ditames da Constituição Federal de 1988, as leis orgânicas de saúde expõem a participação da comunidade como diretriz estruturante para a 
implementação do SUS à luz do princípio doutrinário da democracia participativa e da contribuição social para construção das políticas públicas. A Lei oㅜ 8142, de 1990, dispõe sobre a existência em cada esfera de governo de conferências e dos conselhos de saúde, entendidos enquanto instâncias colegiadas para análise da situação de saúde, proposição de políticas e avaliação de resultados alcançados por tais políticas.

Em consonância com a divisão federativa brasileira, os conselhos funcionam nos níveis local, municipal, estadual e nacional. Trata-se de órgão colegiado de caráter permanente e deliberativo, composto por representantes do governo, dos prestadores de serviço, dos profissionais de saúde e usuários, sendo que a representação destes deve ser paritária em relação ao conjunto dos demais segmentos. Atua na formulação de estratégias e no controle da execução da política de saúde na instância correspondente, inclusive nos aspectos econômicos e financeiros, cujas decisões serão homologadas pelo chefe do poder legalmente constituído em cada esfera do governo. Importa citar que diversos recursos repassados pela União para financiar ações de saúde em outros níveis federativos requerem a existência e funcionamento do conselho de saúde respectivo.

Por seu turno, em harmonia com a divisão federativa brasileira, a Conferência de Saúde se reúne a cada quatro anos com a representação dos vários segmentos sociais, objetivando avaliar a situação de saúde e propor as diretrizes para a formulação da política de saúde nos níveis correspondentes. Ordinariamente, as conferências são convocadas pelo Poder Executivo. A representação dos usuários nas Conferências também deve ser paritária em relação ao conjunto dos demais segmentos.

A deliberação constitucional e infraconstitucional que dispõe sobre a existência das conferências e conselhos de saúde, bem como sobre suas funções, é fruto das batalhas envidadas pelo Movimento de Reforma Sanitária, que atuou fortemente na Oitava Conferência Nacional de Saúde, ocorrida em 1986. Os participantes desta Conferência propuseram que o SUS fosse estabelecido em sede constitucional imbuído dos princípios da universalidade, equidade, integralidade, descentralização da gestão e da execução dos serviços e sob contínua participação popular. Insculpir estes princípios na Constituição Federal foi uma árdua tarefa e grande vitória dos movimentos populares que defendiam um sistema de saúde justo, responsivo aos anseios sociais e que, portanto, nascesse das demandas populares.

Nesse sentido, a diretriz da participação popular, dentre outras funções, amplia - caráter democrático do SUS e estimula a apropriação das deliberações pelos usuários, entendidos como atores que conhecem suas realidades de saúde e os territórios onde as políticas são implementadas, bem como financiam o SUS por meio das contribuições sociais e dos impostos pagos ao Estado. Para Batagelo, Benevides e Portillo (2011), o Brasil oferece lições importantes ao criar mecanismos de participação popular na gestão do SUS, moldando a participação como direito e exemplificando a democracia participativa como fundamental na legitimação das decisões em saúde pública. 
Ao analisar a história do SUS é imprescindível levar em conta os acontecimentos políticos e econômicos vivenciados pelo Brasil nas últimas décadas. Torna-se premente reconhecer que esta política nasceu do clamor popular e que os mecanismos de participação social foram a força-motriz da expansão e do avanço social conquistados nestes 25 anos de história. Todavia, há que se reconhecer que apesar de estar ancorado na constituição e nas leis, existem fragilidades nos mecanismos de participação estabelecidos. Dentre as fragilidades, destacam-se as seguintes: grande parte dos conselhos de saúde registra limitada participação da população, subsiste uma cultura política apoiada em uma tradição autoritária, registra-se uma deficiente capacitação técnica e política dos conselheiros, em especial no segmento dos usuários, e, ainda, observa-se uma patente falta de paridade na composição de vários conselhos cujos critérios de escolha dos membros ainda são obscuros, e, principalmente, verifica-se a assimetria das informações entre os diversos segmentos que compõem este órgão de participação social (Santos; Bastos, 2011).

Noutro cenário, parece existir uma concorrência de atribuições entre os conselhos de saúde e os poderes executivo e legislativo. A Lei ํo 8142 , de 1990, estabelece que os conselhos de saúde são de caráter deliberativo, cabendo ao chefe do poder executivo homologar suas deliberações. Nesse sentido, os conselhos possuem a responsabilidade por decidir sobre os temas da saúde e o poder executivo a obrigação em acatar tais decisões. Por outro lado, na estrutura federativa compete aos executivos federal, estadual e municipal, definir e executar as alocações orçamentárias, objetos de acompanhamento e fiscalização dos conselhos (Bispo Júnior; Gerschman, 2013).

O SUS enfrenta diversos desafios. Vale citar a necessidade de ampliar a base de financiamento das ações de saúde, a requerida mudança do modelo assistencial, a necessária qualificação da gestão e a urgente promoção da equidade na distribuição da capacidade instalada para população. Há graves distorções na distribuição dos recursos humanos e materiais em função dos critérios demográficos e de demanda das populações. Acredita-se que a efetivação da diretriz da participação popular seja um passo essencial para o alcance dos demais objetivos do SUS.

A participação social no sistema de saúde é condição fundamental para o exercício pleno da saúde e da democracia, capaz de promover a equidade e a transformação da atenção à saúde no Brasil. Os espaços dos conselhos e conferências de saúde são locais de escuta da sociedade civil que partindo da apropriação coletiva da situação de saúde contribui com a criação, execução e avaliação de políticas públicas que impactam diretamente na saúde da população brasileira. Dessa forma, é inegável que a efetiva participação da comunidade é um objetivo a ser perseguido pelo SUS e por todas as políticas públicas (Coelho, 2012).

Ampliar a participação comunitária no seio das políticas públicas, solidificando seus espaços de controle e atuação e mitigando suas fragilidades é um desafio que se impõe ao Estado brasileiro. Os conselhos devem expandir suas articulações com os movimentos sociais, com os órgãos de controle interno e externo da Administração 
Pública e com organizações não governamentais como estratégia imprescindível ao desenvolvimento dos mecanismos de participação social, com vistas ao adequado desempenho de sua finalidade social e ao estabelecimento de novas relações da população com o Estado.

O processo de elaboração, execução e avaliação das políticas de saúde deve entender a participação popular como um direito social e um instrumento viável para inclusão de novos atores no debate em saúde. Dessa forma, o Estado ampliará sua capacidade de estabelecer políticas públicas sociais economicamente viáveis, transversais e responsivas aos anseios da população sem desprezar, contudo, a sobredeterminação dos fatos históricos no objeto de criação e transformação da política pública.

\section{Considerações finais}

O Movimento pela Reforma Sanitária no Brasil prenunciou um novo momento histórico caracterizado pela redemocratização do Estado e das políticas públicas, em especial da atenção à saúde. Evidencia-se, assim, que o SUS constitui a organização do Estado e da sociedade para execução da política de saúde no Brasil e reflete fatores históricos e sociais que permearam a discussão, construção e reconstrução deste modelo de atenção à saúde.

A participação social é um elemento essencial para alcance de diversos dos objetivos do SUS e para o fortalecimento do mesmo com vistas à plena aplicação de seus princípios doutrinários e organizativos. O Brasil detém uma experiência marcante no uso da participação social para construção de sua maior política social, que alcança toda sua população e aceita o desafio de ser universal, integral, equânime, descentralizada e responsiva às demandas apresentadas diretamente pela sociedade.

Fortalecer os Conselhos e Conferências de Saúde, enquanto espaços de escuta e de apropriação coletiva das decisões é um desafio ao Estado brasileiro. Trata-se de um passo essencial para ampliação da participação comunitária nas políticas públicas, solidificando seus espaços de controle e atuação e mitigando as fragilidades impeditivas do efetivo desempenho da democracia participativa.

\section{Referências}

AMORIM, Camila Rego [et al.] Participação e Mobilização Social no SUS: Entraves, Desafios e Perspectivas. Rev. APS [on line], 15(3): 294-298, jul/set, 2012. ISSN 14152177. Disponível em: http://pesquisa.bvsalud.org/portal/resource/pt/lil-655251 [data da consulta: 02 jul. 2014].

BATAGELLO, Rodrigo; BENEVIDES, Luciana e PORTILLO, Jorge Alberto Cordón. Conselhos de saúde: controle social e moralidade. Saúde soc. [online]. 20(3): 625634, 2011. ISSN0104-1290. Disponível em: http://www.scielo.br/scielo. php?script=sci_arttext\&pid=S0104-12902011000300009\&lng=en\&nrm=iso [data da consulta: 02 jul.2014].

BISPO JUNIOR, José Patrício e GERSCHMAN, Sílvia. Potencial participativo e função deliberativa: um debate sobre a ampliação da democracia por meio dos 
conselhos de saúde. Ciência \& Saúde Coletiva [online]. 18(1):7-16, 2013. ISSN14138123.Disponível em:http://www.scielosp.org/scielo.php?script=sci_arttext\&pid=S141381232013000100002\&lng=en\&nrm=isso [data da consulta: 02 jul.2014].

BRASIL. Lei no 8080/90, de 19 de setembro de 1990. Dispõe sobre as condições para a promoção, proteção e recuperação da saúde, a organização e o funcionamento dos serviços correspondentes e dá outras providências. (Lei Orgânica da Saúde). Diário Oficial [da] República Federativa do Brasil, Brasília, 20 set. 1990. Disponível em: http://www.planalto.gov.br/ccivil_03/Leis/L8080.htm [data da consulta: 02 jul. 2014].

BRASIL. Lei n ${ }^{\circ} 8142 / 90$, de 28 de dezembro de 1990.Dispõe sobre a participação da comunidade na gestão do Sistema Único de Saúde (SUS) e sobre as transferências intergovernamentais de recursos financeiros na área da saúde e dá outras providências. (Lei Orgânica da Saúde). Diário Oficial [da] República Federativa do Brasil, Brasília, 31 dez. 1990. Disponível em: http://www.planalto.gov.br/ccivil_03/Leis/L8142.htm. [data da consulta: 02 jul.1990].

BRAVO, Maria Inês Souza e CORREIA, Maria Valéria Costa. Desafios do controle social na atualidade. Serviço Social \& Sociedade. [online], (109):126-150, 2012. ISSN0101-6628.

Disponível

http://www.scielo.br/scielo.php?script=sci arttext\&pid=S0101-

66282012000100008\&lng=en\&nrm=iso [data da consulta: 02 jul. 2014].

BRUTSCHER, José Volmir. Gestão, Direito e Participação no SUS. Revista Brasileira de Ciências da Saúde [on line], 6(3):401-410, 2012. ISSN1415-2177. Disponível em: http://periodicos.ufpb.br/ojs2/index.php/rbcs . [data da consulta: 02 jul.2014].

COELHO, Juliana Sousa. Construindo a participação social no SUS: um constante repensar em busca de equidade e transformação. Saúde \& Sociedade [online], 21(1): 138-151, 2012. ISSN0104-1290. Disponível em: http://www.scielo.br/scielo. php?script=sci_arttext\&pid=S0104-12902012000500012\&lng=en\&nrm=iso [data da consulta: 02 jul.2014].

SANTOS, Cibelle Cristina da Silva Santos e BASTOS, Raquel Littério. Participação Social: A Construção da Democracia na Saúde Brasileira. RBPS, 24(3):266-273, jul/set, 2011.Disponível em: http://pesquisa.bvsalud.org/portal/resource/pt/lil-602540 [data da consulta: 02 jul. 2014].

ROLIM, Leonardo Barbosa; CRUZ, Rachel de Sá Barreto Luna Callou e SAMPAIO, Karla Jimena Araújo de Jesus. Participação popular e o controle social como diretriz do SUS: uma revisão narrativa. Saúde em Debate [on line], 37(96):139-147, 2013. ISSN 0103-1104. Disponível em: http://www.scielo.br/scielo. php?script=sci_arttext\&pid=S0103-11042013000100016\&lng=en\&nrm=iso [data da consulta: 02 jul.2014]. 